\title{
O dito originário da linguagem
}

Armando Edson Garcia Universidade Tuiuti do Paraná 


\section{Resumo}

O objetivo aqui proposto é identificar o conceito do Dito originário, a partir da temática heideggeriana, verificar sua lógica própria e procurar entender, com isto, as reflexões de Mélanie Klein a respeito do "corpo imaginado" lançado "num mundo. Nossa reflexão alcançará um segundo objetivo que é o de oferecer bases lógico-temáticas tanto para a confecção, como para a abordagem textual. O processo da produção do texto estará, então, entendido como o resultado de uma particular atividade operacional da mente. A operação mental e seu produto são correlatos. A temática, no nível de sua "originariedade" transcendental, será um falar que é também, e simultaneamente, um escutar a palavra em sua proposta. $O$ ser deixa-se dizer na eloquência da linguagem fundadora. $E$ para que se apreenda um texto, marcado por esta lógica, há que se colocar, na leitura, no mesmo ritmo lógico de sua confecção.

\section{Palavras-chave}

lógica textual, lógica e linguagem, lógica e hermenêutica, ser e linguagem originária

\section{Abstract}

The objetive proposed here is to identify the concept of the originator Dito (Die Sage) starting from the heideggerian thematic, to verify its own logic and to try to understand, based on these notions, Mélanie Klein's reflections regarding the "imagined body" launched in a world. Our study intends to reach a second objetive, which is to offer logicthematic bases for the making and also the textual approach. The process of text production will be, then, understood as a result of a specific operational activity of the mind. The mental operation and its product are correlated. The thematic, in the level of its trasnscendental originality, will be a speaking which is also, and simultaneously, a hearing the word in its proposal. The being let itself say in the eloquence of the founding langage. And in order to apprehend a text inscripted by this logic, one has to follow, in the reading, the same logical rhythm of its making.

\section{Key words}

textual logic, logic and language, logic and hermeneutics, being and original language 


\section{Introdução}

A hipótese que nos conduz neste artigo diz que o que sustenta o sentido e a intenção do texto é uma matriz lógica. Daí que 1 um texto só poderá ser compreendido e interpretado em sua intenção fundamental, na condição de se perceber a lógica que o gerou.

Tomando de empréstimo a tese cartesiana de N. Chomsky, podemos dizer que o espírito humano tem uma atividade de conhecimento que se modela na linguagem. A auto-modelação do espírito (e o espírito aqui é a mente), através da linguagem, é feita a partir daquilo que Humboldt designa como "forma", isto é, regras e princípios subjacentes ao espírito correspondentes aos tipos de estruturas mentais responsáveis pela atividade conhecedora do ser humano (ap. Chomsky, 1971, p. 1).

Vamos utilizar este ponto de vista para tentarmos um acesso à linguagem como Dito, em sentido heideggeriano. O Dito nos coloca no âmbito da linguagem em que somos inseridos desde sempre em um mundo (em sentido heideggeriano). Esta originariedade ontológica nos remete também para a originariedade genética do ser. E em sua originariedade, o estar sendo do ser pode ser visto como um texto que se lê. E este texto é um comportamento. Texto-comportamento portador de um significado e de informações. Se aí há um texto é porque há um tema. E se há um tema, há uma articulação que o sustenta. A articulação pressupõe regras que conectam os termos que compõem o tema.

$\mathrm{Na}$ articulação do tema está a habilidade operacional da mente . Alguém tece sua própria expressão. Roland Barthes faz eco ao conceito do Dasein, em Heidegger: 
Texto quer dizer Tecido... perdido neste tecido - nesta textura - o sujeito se desfaz nele, qual uma aranha que se dissolvesse ela mesma nas secreções construtivas de sua teia (Barthes, 1973, pp. 100-101).

A teia é a aranha no momento seguinte. A teia é já a aranha como legível, auto-elaboração de si para dentro do mundo simbólico.

Esta auto-elaboração do ser para dentro do mundo simbólico é sempre complexa, mas poderíamos, metodicamente, dividi-la em etapas: etapa uterina, etapa que vai do nascimento aos 18 meses de idade (mais ou menos), etapa que vai dos 18 meses em diante. A cada etapa corresponde um tipo de linguagem, respectivamente: a linguagem do Dito, a linguagem do Signo, a linguagem da Discursividade.

Em cada uma destas etapas, o indivíduo desenvolve operações mentais específicas que vão articular os diversos comportamentos próprios à respectiva etapa. A atividade mental é um logos ativo. Em termos de comportamento, trata-se de um saber de que se reveste o sujeito no seu dar-se como presença no mundo expressivo. E este saber é a expressão de um tema. E o tema tem sua articulação própria na expressão do corpo próprio.

\section{O "corpo imaginado"}

A criança no seio materno não é simplesmente um organismo celular vivo, em termos biológicos. É bem mais do que isso. Melanie Klein entende esse pequeno ente como um "corpo imaginado" (1984, p. 26). É então que, a mãe, durante a gestação, e já antes dela, lança sobre este entezinho um conjunto de imagens que correspondem a suas fantasias e expectativas. É esta idealização que deborda, ao entezinho, uma dimensão para lá do estritamente biológico. O entezinho traz consigo, ao nascer, uma "visão" do eu mundo, de tal modo que pode entender o nascimento como ameaça, e visualizar o estado pré-natal como um estado ideal de vida.

A verbalização posterior do adulto, de suas fantasias e temores nesse estado pré-natal, não têm explicação suficiente se tomarmos o caminho da explicação mecanicista dos estados mentais, 
que se apóia na introjeção de impressões vindas do exterior estimulando a atividade mental em termos de memorizações e associações. É esta, por exemplo, a explicação de Skinner em seu Verbal Behavior (ap.Chomsky, 1964).

Trata-se na verdade, de dar uma explicação para um saber próprio do indivíduo na vida intra-uterina. Este saber não é simplesmente fruto de uma memorização da experiência aí vivida, mas é, antes, um conhecimento que se originou pelo fato de o indivíduo ter em funcionamento, nesta fase, uma operação mental que lhe permite algo como a experiência da vida uterina. Esta experiência é o saber como um conhecimento (não objetivo) elevado à esfera de "idealização da bolsa" ou do estado pré-natal. Esta operação mental tem uma estrutura própria, sua regra fundamental de articulação. Neste estágio, a operação mental não se verifica por uma atividade cerebral. $\mathrm{O}$ embrião não tem cérebro ou um sistema nervoso central explícito. O óvulo fecundado detém uma estrutura dos princípios operatórios "mentais" já em programa e, em seu nível, operando nesses momentos iniciais. $\mathrm{O}$ entezinho que surge traz não só a carga genética do pai e da mãe, mas também a articulação dos desejos e sonhos de um e de outro. E nisto está um pronunciar originário onde se aloja, por solicitado, o novo entezinho. Nisto ele é "corpo imaginado", um Dito heideggeriano.

\section{O ser "lançado" num "mundo"}

O pequeno ser, como ser pronunciado, foi lançado num mundo. Neste enunciado se escondem duas coisas importantes: a dimensão da linguagem em que estamos inseridos desde sempre, e a dimensão de um mundo em que nos situamos como condição definitiva de existência. Por ora ficamos com a dimensão do "mundo", e exploramos sua constituição para aquilo que interessa à leitura de um texto-comportamento.

De que mundo se trata? A bolsa uterina, para o entezinho, é um ambiente sem luz, sem luz, sem formas espaciais. À sua capacidade perceptiva, neste momento, tais coisas espaciais não contam. O "mundo" a que é lançado o entezinho não é aqui um mundo concreto, espacializado, cheio de coisas. Não é um lugar. Na verdade, 
trata-se de uma dimensão nova, trata-se do mundo como horizonte sem fim, de onde nascem todas as esperanças, uma dimensão do imponderável, cujo ritmo é o de um pulsar capaz de criar todas a utopias. É verdadeiro para este "mundo" tudo que se revela como tendo um sentido no interior deste mesmo "mundo". A verdade se revela no interior deste "mundo", se mostra, enquanto dá à luz a um todo envolvente, a uma totalidade, não das coisas, mas a uma totalidade do uno: há uma unidade do todo. A unidade fundamental de si, esta é a verdade que se mostra no mundo de antemão dado ao entezinho, que se faz agora mensagem. Ele é notícia de um mundo mais vasto que o mundo material.

As utopias e esperanças latentes na dimensão deste mundo são expressões da liberdade como dom do novo ser. A liberdade se agita no interior deste horizonte como uma possibilidade das mesmas dimensões. Por estar inserido no horizonte desse "mundo", o novo ser é dotado de um olhar que o lança na posse desde já de todo seu futuro. Tudo o que tem a ser é seu futuro que, desde sempre, se lhe faz presente, um universo indizível prodigalizando aquela unidade e segurança, de que a bolsa uterina é para nós o símbolo imediato em sua esfericidade. A esfera conduz à forma do "zero" e o zero em filosofia não ó o indicador do vazio de coisas inexistentes. O zero aponta para a "terceira margem do rio", no dizer de Guimarães Rosa, isto é, aponta para uma dimensão que não é esta aqui, nem aquela lá, mas uma outra, indizível, incompreensível para os sentidos. Pois bem, esta esfericidade é de nível zero, é uma dimensão no interior da qual tudo adquire sentido. Heidegger vai dizer: "sem a originária revelação do nada, não há ser-si-mesmo, nem liberdade" (1973, p. 225).

Melanie Klein entende que é a mãe quem propicia para a criança este "mundo envolvente", essa nova dimensão do ser, pela articulação da linguagem. Trata-se de uma articulação que faz presente este "mundo", Dá-se um presentar que propicia a presença, o ser deste entezinho.

De dentro da presença fala o tempo que diz "presente". É assim que, por trás da presença oculta-se o presentar, o que sustenta a presença, ou, ainda, por trás da presença oculta-se o tempo, não o 
tempo cronológico, mas o tempo como permanecer. O presentar do tempo, o presentificar, é o desvelar da presença, esta como instituição do ser. "Ser" é o destino do ente; o tempo é o permanecer e o presentificar do destino, ou seja, é o destinar do destino. Enfim, o tempo como presentificador revela o "mundo".

$\mathrm{O}$ "tempo" deve ser entendido como uma atividade (operador) que propicia o advento do "Ser", o argumento em termos de resultado desta atividade; o tempo abre o mundo para o entezinho. Agora podemos entender o que Heidegger, em Tempo e Ser, repetia metodicamente: "Dá-se ser; dá-se tempo." (1973, p. 453 e ss.).

Portanto, desde a origem, o homem é abordado por esta presença. Por ser abordado se presenta. Ouçamos esta passagem: " $O$ homem está postado de tal modo no interior da abordagem pela presença, que recebe como Dom o presentar que dá-se, enquanto percebe aquilo que aparece no presentificar"(Heidegger, 1973, p. 461).

A abordagem é a atividade da linguagem, o pronunciar, que aborda o entezinho, e o conduz ao seu advento (é o operador identidade). Desde seus inícios, o homem é dotado de um dom, uma capacidade operatória que o sustenta no mundo, isto é, seu destino, no ser, já é para sempre dado. Sem isso, "o homem não seria homem" (Id., ib.).

$\mathrm{Na}$ medida em que a presença do muno, ou o mundo como presença, oculta o presentar, e na medida em que o presentar sustenta a presença, temos a mútua referência do presentar e da presença, do tempo e do ser: o Ser é constituído ocultamente de tempo, por trás do Ser fala o tempo. Um não se dá sem o outro: Ser é Tempo. Ser e Tempo, o mesmo. Esta é a primeira característica do Ser, segundo Heidegger: sua ipseidade.

Uma segunda característica é a existência, o estar jogado na abertura do ser, ou no umbral do ser. O umbral é onde alguém está situado "fora" (ou dentro). O ex-sistente é o ek-stático, onde o "ex-" ou o "ek-" indicam o "fora" de uma situação (stasis). O entezinho passa a ser-aí, porque sai fora de uma situação e se aloja na abertura ("â̂") de um "mundó", onde está "ek-staticamente" presentado, onde vem à luz e se dá a revelar e se mostra em sua verdade. Porque vem para fora, no mundo do Ser, o ser-aí é “ex-sistência” (cf. Heidegger, 1964, passim). 
Uma terceira característica fundamental do ser-aí é designada como a sua essencial neutralidade (Heidegger, 1928, p. 171175, ap. Franck, 1986, p. 32; 55). Esta característica vai esclarecer a diferença que estamos até agora reforçando, isto é, a vida estritamente biológica não explica tudo no homem e nem é o mais importante. É preciso reconhecer a dimensão própria do "mundo" inaugural que eleva o entezinho ao status de "ser-ấ".

A neutralidade do ser-aí indica precisamente que a carne e a sexualidade (a diferença sexual) não podem por si próprios conduzir o homem à esfera do "mundo", do ser. É assim que Heidegger procura exprimir esta idéia:

A neutralidade específica do título "Dasein" é essencial porque a interpretação deste ente deve ser realizada antes de toda concreção factual. Esta neutralidade significa também que o Dasein não nenhum dos dois sexos. Mas essa assexualidade não é a indiferença da nulidade vazia, a impotente negatividade de um nada ôntico indiferente. $O$ Dasein em sua neutralidade não é indiferentemente ninguém e todo mundo, mas a positividade e o poder originários da essência (ap. Franck, 1992, p. 136).

O Dasein neutro é sem dúvida a fonte primária da intrínseca possibilidade que aflora em cada existência e torna-a intrinsecamente possível. O Dasein abriga a possibilidade intrínseca de ser factualmente disperso na corporeidade e por isto na sexualidade ( $i d$., $i b .$, p. 137).

O que aí se pretende definir é o âmbito próprio da lógica transcendental. Ela define um campo anterior, em termos lógicos tão somente, à "toda concreção factual" que é do domínio das lógicas da diferença. Por isto mesmo, o Dasein não é nenhum dos dois sexos. Além do mais, Dasein também não é a "consciência", algo inscrito na historicidade da lógica da diferença, o mundo da espacialidade. Ora, o Dasein neutro implica apenas o conceito de "tempo", e não o de espaço. O Dasein é uma ipseidade neutra existente.

A definição da neutralidade do ser-aí só pode ser entendida se for situada em seu momento próprio: na origem mais fundamental 
da vida de todo homem. Um momento a partir do qual tudo começa a ter significado, e o olhar interpretativo marca sua presença ao alojar, a partir daí, todas as impressões vindas do exterior, todas as experiências, no interior do "mundo" inaugural, no interior do próprio destino individual. Em suma, em "A essência do fundamento" temos:

É somente porque o Dasein como tal é determinado pela ipseidade que um eu-mesmo pode estar em relação com um tu-mesmo. A ipseidade é a pressuposição para a possibilidade da egoidade que não se revela jamais senão no tu. Mas a ipseidade não está jamais ligada ao tuela o torna possivel -, ao contrário ela é neutra com relação ao ser-eu e ao ser-tu, mais ainda com relação 'sexualidade (ap. Franck, 1986, p. 33).

Assim, só é possível a lógica da diferença (D) se houver de antemão a lógica da identidade (I).

O mundo originário abre o horizonte que propicia ao indivíduo chegar ao status de sua maturidade, passando por diversas fases intermediárias, tais como a percepção do outro na diferença eutu, a assimilação da diferença socializada do sexo. O ser-aí, em sua neutralidade, encerra aquilo que Heidegger chama de "dispersão factual", as possibilidades da diferença eu-tu, da diferença sexual e outras. O ser-aí como factual "é sempre disperso em uma carne e ao mesmo tempo sempre dividido numa sexualidade determina$d a$ " (1992, ap. Franck, 1986, p. 15). Heidegger reconhece que a espacialidade (Lógica da diferença) se aloja no âmago do "tempo" (Lógica da identidade). Tal espacialidade ele designa como "dispersão transcendental" (Zerstreuung); trata-se de uma "disseminação" (Streuung) originária e neutra. Em definitivo, o ser-aí é lançado num mundo e este mundo the prodigaliza tudo o mais. E como se tudo acontecesse no interior de uma imensa e luminosa esfera. É ela que permite perceber as formas e os sentidos. Tudo se desdobra a partir da esfera e no seu interior. Nas palavras originais: "Ter ele um mundo ambiente (Umwelt) só é possível na constituição existencial do ser-no-mundo" (Heidegger, 1964, p. 80). 


\section{A linguagem como Dito}

Dissemos que o que constitui o entezinho, desde o primeiro momento da concepção, é ser "pronunciado", ser "jogado" para dentro de um "mundo". Por este mundo, tudo se torna luminoso. Por ser pronunciado, uma palavra o trouxe à luz da vida, à luz do ser. $\mathrm{O}$ "mundo" é o horizonte de seu poder-ser. Suspenso no interior deste "mundo", o entezinho repousa na palavra, habita a palavra (Cf. Heidegger, 1984).

Ernst Cassirer, em Linguagem e Mito, relata que os índios Uitoto têm uma passagem, a nós familiar, que diz: "No princípio a Palavra se originou do Pai" (Cassirer, 1972, p. 64). Neste mesmo ponto, o autor faz notar que os relatos da criação de quase todas as grandes religiões culturais, fazem a palavra aparecer sempre unida ao mais alto Deus criador. Cassirer informa ainda que na Índia, o poder do Discurso (palavra) vem antes do poder dos próprios deuses:

Do Discurso dependem todos os deuses, todos os animais e todos os homens...

O Discurso é o imperecível, é o primogênito da Lei eterna, a mãe dos Vedas, o umbigo do mundo divino (ap. Cassirer, op. cit. p. 66).

E mais, a palavra, em outros casos, aparece como força primordial, por cujo único intermédio o caos pode transformar-se em cosmos moral-religioso. Cassirer chama a atenção para o fato de que alguma coisa confere à palavra esse poder criador, esse caráter sagrado. É um poder que se revela ao ser pronunciado. A palavra, por ser pronunciada, cria o mundo e ordena o caos. Ela é o primogênito, a possibilidade fundamental (tempo) para que todo as coisas possam existir (espaço).

Não é difícil constatar nos mitos antigos que se trata da palavra originária, pronunciada para cada homem, a fim de que haja para ele "mundo", e com o "mundo" possa apreender as formas de todas a coisas. O novo ser é, desde o início, um ser de linguagem: ao ser pronunciado, também se pronuncia.

O conceito de "Dito" (Die Sage) elaborado por Heidegger traduz para nós o significado de "palavra originária" que conforma 
um mundo. Dito é um termo que vem de dizer (Sagen), que no antigo alemão significava mostrar. O Dito mostra, revela, desvela, descobre o que estava encoberto. No Dito "repousa a palavra em seu desdobramento", ou seja, o primeiro modo de a palavra (a linguagem) se apresentar é como Dito. O Dito funda o início de tudo. Só depois o outros modos de linguagem serão possíveis:

O que se desdobra na palavra é o Dito enquanto mostra: "...todos os signos se originam de um mostrar, no horizonte e pelas intenções do qual somente eles podem ser signos" (Heidegger, 1984, pp. 240-241).

A palavra (a linguagem originária) em seu desdobramento, em seu mostrar, é um traçado-abridor, isto é, abre um sulco como aquelas máquinas na lavoura abrem sulcos para pôr sementes e fazer aparecer o que foi plantado. $O$ traço ou o sulco revelam, dão à mostra. O dito é o modo inicial fundamental pelo qual a linguagem inaugura sua tarefa de abrir sulcos, os quais deveram o ser e suas possibilidades. Os falares de todos os tipos, as linguagens de diversos níveis, têm sua fonte no Dito: "Seu dizer tem sua fonte no Dito um dia falado e até este dia ainda in-falado, que atravessa e liga o traçado-abridor da palavra em seu desdobramento" (Id., ib., p. 241).

Dissemos que o presentar (tempo) aborda e sustenta o ser. Mas o ser-aí (o entezinho) está de tal modo no interior desta abordagem que recebe como Dom a capacidade de "presentar", isto é, ele vem dotado da capacidade lógico-operatória que chamamos I (lógica da identidade). Operar lógico-operatoriamente no nível originário é expressar-se na linguagem do Dito. Quando dizemos que o presentar aborda o ser, também estamos dizendo que o falar aborda o ser. E falar é a mesma coisa que escutar. Não no sentido de que alguém fala e outro escuta numa conversa cotidiana. Falar e escutar se dão ao mesmo tempo.

É no escutar da palavra que nós falamos. O escutar da palavra originária pelo ser-aí é sustentar o Dito, é falar trazendo à luz o que se revela. Por isso também já dissemos que o ser-aí, porque abordado pelo presentar, recebe como Dom o presentificar, isto é, 
porque lançado pela palavra, o ser-aí recebe como Dom o falar, porque também é capaz de escutar. Escutar é a atitude fundamental de se-deixar-dizer, pelo que o mundo próprio de ser vem de se mostrar à luz da existência. O escutar é a eloquência do ser-aí do entezinho que se faz linguagem ao modo da chegado do ser. O ser-aí é como o ser se diz na sua linguagem apropriada. O escutar é proferir o ser e o "mundo'.

Enfim, o entezinho, lançado pela palavra no "â̂" do "mundo" como seu próprio destino e alcance de ser, enquanto escuta, expressa o Dito fundamental; deixa-se dizer na eloquência da linguagem fundadora. Falar-ouvir é o operatório que sustenta a presença que se mostra à luz da linguagem do dito.

\section{Conclusão}

O dito originário, portanto, não é o ruído e os sons vocais das conversas diárias. $\mathrm{O}$ dito originário é tudo o que o entezinho exprime a partir de si para si mesmo. Seu próprio universo de ser e poder-ser, porque o dito também contém toda percepção e toda representação.

$\mathrm{O}$ Dito exprime uma totalidade sem divisões, a unidade passado-presente-futuro como presente (o tempo), o "mundo" em que se aloja o ser-aí, o ser que mostra na dimensão do ser-aí, o modo fundamental do entezinho. O Dito é o comportamento originário e inicial, é a expressão fundante.

Tais são os temas interligados do Dito originário: o tempo, o destino, o nada, a totalidade, o falar e o escutar. A Lógica da identidade é o modo de abordagem dessa temática, no nível fenomenológico.

É a linguagem como Dito que confere ao homem sua especificidade. É o Dito que torna possível a linguagem (de qualquer nível) e a meta-linguagem. Enfim: "A palavra permanece, portanto, indubitavelmente ligada ao poder humano de falar" (Id. ib., p. 242). 


\section{Bibliografia}

CASSIRER, Ernst. 1972. Linguagem e mito. São Paulo: Perspectiva.

CHOMSKY, Noam. 1971. Lingüística cartesiana. Petrópolis: Vozes.

1964. A Review of Skinner's Verbal Behavior. In: FODOR, J.; KATZ. J. The structure of language: Readings in philosophy of language. New Jersey: Prentice-Hall.

FRANCK, Didier. 1986. Heidegger et le problème de l'éspace. Paris: Minuit.

HEIDEGGER, Martin. 1992. The methaphysical foundations of logics. Bloomington and Indianapolis: Indiana University Press.

. 1964. L'être et le temps. Paris: Gallimard.

. 1984. Acheminement vers la parole. Paris: Gallimard.

. 1973. Tempo e ser. In: Os pensadores. São Paulo: Abril, v. 45, p. 453-470.

KLEIN, Melanie. 1984. Inveja e gratidão. 2. ed. Rio de Janeiro: Imago. 